\title{
PAPEL DA RAZÃO \\ E DO SENTIMENTO NA PROPOSTA ÉTICA DE TUGENDHAT
}

\author{
Martina Korelc \\ U niversidade Católica de Goiás \\ comloy@terra.com.br
}

\begin{abstract}
RESU M0: 0 texto pretende explicitar como, segundo Tugendhat, se dá a justificação da moral, intrín seca aos juízos morais, através de uma imbricação dos elementos racional e emotivo. 0 s juízos morais, enquanto procedimento racional, contêm uma pretensão de objetividade, que se pode explicar pelo imperativo categórico kantiano, interpretado como um exigir mútuo do respeito universal eimparcial aos interesses detodos. A obrigatoriedade moral, porém, pressupõetambém um querer fazer parte de uma comunidade moral, a partir da qual os juízos morais passam a vincular emotivamente, através da interiorização dos sentimentos que acompanham o aprovar eo desaprovar moral. Essa explicação das exigências morais parece satisfatória para a justificação de um núcleo mínimo de normas morais partilhadas numa dada sociedade; o texto aponta para a problematicidade dessa justificação da obrigatoriedade moral nos casos em que faltam regras partilhadas ou quando se considera a não-identificação das exigências morais com o queéempiricamente aprovado na sociedade.
\end{abstract}

Palavras-chave: juízos morais, razão, sentimento, justificação, intersubjetividade.

\section{Introdução}

No presente texto, proponho-me a discernir e descrever 0 elemento racional e afetivo na proposta ética de $E$. Tugendhat, como ele a expõe no seu livro Lições sobre ética. 0 objetivo de Tugendhat nesta obra é esclarecer o que poderia significar fundamentar uma moral moderna, isto é, propor uma fundamentação quenão seria mais de tipo tradicional, religiosa ou pseudo-religiosa. A questão da fundamentação é para este autor uma questão fundamental, por ser intrínseca à própria compreensão da moral, ao próprio fato moral. Pois, uma vez que os nossos juízos morais - e estes são elemento essencial da moral - têm a pretensão de ser universal mente válidos e objetivos, a sua validade para nós deve ser fundamentada. "É possível julgar moralmente sem acreditar que 0 
seu julgamento está fundado?", pergunta o autor na primeira das lições. Talvez essa necessidade de justificação esteja expressa ainda melhor num outro texto do autor:

Em nenhuma moral se crê que os padrões de justiça, assim como também o resto das normas morais, sejam simples convenções. Toda moral, e por isso também todos os padrões de justiça, têm sempre a pretensão de serem justificados. Os membros da comunidade têm que subordinarse ao sistema de normas em que consiste uma moral, e sendo as normas sempre algo que limita a liberdade de cada um, cada qual necessita de uma razão, de uma justificativa para subordinar-se. ${ }^{1}$

N esta obra, o autor aborda a justificação como que em dois níveis diferentes: um poderia ser a justificação dos juízos morais que está intrínseca no próprio fato moral, no próprio juízo, como o ilustram as citações; o outro nível é a justificação da moral como um todo, a explicação do fato moral que compete com as outras explicações, com outras éticas e, portanto, outras propostas de justificação. N esse sentido, 0 autor discute com muitas propostas éticas a fim de argumentar a favor da maior plausibilidade da sua proposta. N este trabalho, prestarei atenção ao primeiro sentido da justificação, para compreender como se dá, segundo o autor, em termos de razão e sentimento. A pergunta pelo papel da razão e do sentimento na moral leva também para além do próprio problema da justificação. Tenho consciência de que uma distinção nítida dos papéis, como pretendo que seja descrita aqui, na primeira parte do trabal ho, para o tornar claro, pode resultar, al gumas vezes, artificial. É, pois, somente um recurso metódico.

\section{Entre razão e sentimento}

I -Como Tugendhat define uma moral como "o conjunto de juízos morais de que al guém ou um grupo dispõe", ${ }^{2}$ naturalmente 
se empenha por explicar o que são juízos morais. N os juízos morais 0 elemento racional está fortemente presente. Por isso nós 0 acompanharemos na sua caracterização, neste primeiro momento, prestando atenção sobretudo ao papel da razão.

Juízos morais são juízos com os quais exprimimos que algo, uma ação, é boa ou má, permitida ou proibida. Neles usamos palavraster deou deve ou não pode, bom ou mau, num sentido particular, diz Tugendhat, isto é, com um sentido absoluto. A característica fundamental dos juízos morais é que el es exprimem uma pretensão devalidade absoluta e universal, não relativa à nossa pessoa. Q uando avaliamos moralmente, temos a pretensão de que o nosso juízo seja objetivo, com validade universal, portanto, que ele seja fundamentado. Isto não é apenas uma particularidade lingüística, uma curiosidade do emprego das palavras, mas diz respeito à nossa compreensão da moral, ao próprio sentido da moral. Esclarecer este emprego absoluto dos termos valorativos e de ter de moral, a preten são da objetividade, significa esclarecer o caráter da obrigação relacionado com a moral, é o caminho da compreensão da justificação na moral.

0 ter de ou deve exprime, geralmente, uma regra. A explanação que Tugendhat faz de tipos de regras nos ajuda a compreender de que modo a racionalidade está presente na moral. Para além das regras chamadas "teóricas", construídas racionalmente a partir da observação das regularidades na natureza, por exemplo (leis da natureza), existem regras práticas que dizem respeito a ações a serem seguidas. Entre estas, Tugendhat chamou de "regras de razão" aquelas regras que exprimem o que é razoável ou necessário fazer em vista de um determinado fim prático. Se pretendemos um fim, a razão "manda" ou orienta a realizar determinadas ações necessárias para alcançar o fim; seria irracional pretender o fim e não fazer 0 que é necessário para al cançá-lo, segundo o "sentido comum da racionalidade": consistência entre as nossas metas e o nosso agir. Se a regra não é seguida, a sanção que se segue consiste em não ser alcançado o fim. U m outro tipo de regras práticas são "regras de 
jogo" que são construídas pela razão, porém arbitrariamente, sem contemplar al guma necessidade prática. 0 ra, as regras morais são um tipo de "regras (práticas) sociais", que também ordenam ou proíbem realizar algo, um tipo de comportamento e contam com algum tipo de san ção, caso não sejam cumpridas. 0 comportamento social dos indivíduos é, portanto, regido pelas regras ou normas, entre as quais Tugen dhat distingue normas jurídicas, convencionais e morais. Elas se distinguem entre si pelo tipo de sanção, ${ }^{3}$ mas também pelo modo como a sociedade justifica as próprias regras, 0 que se torna a diferença mais importante. Essas regras certamente são racionais, no sentido de serem elaboradas racionalmente, com o intuito dealgum fim. Porém sua fundamentação não étão-somente racional, como acontece no caso das normas "de razão". ${ }^{4}$ Tornar claro o tipo de fundamento implicado nas normas morais é 0 objetivo de Tugendhat. Enquanto as regras convencionais não podem nem pretendem ser justificadas para além da própria convenção, ou seja, elas exprimem a aprovação ou a rejeição de uma conduta pela sociedade e nada mais, a própria rejeição social é o fundamento da regra convencional, nas normas morais a rejeição ou a aprovação da conduta pela sociedade pretendem ser ulteriormente fundamentadas num conceito do que é bom ou mau: " $\mathrm{A}$ rejeição na infração de uma norma moral, ao contrário, fundamentase obviamente [...] no fato de a gente achar ruim um semelhante procedimento". ${ }^{5}$ Isto conduz o autor à compreen são do sentido dos conceitos bom e mau ou do nosso avaliar algo como bom ou mau. Entretanto, tornou-se claro para o autor que 0 sentido gramaticalmente absoluto do ter de moral está relativizado pela sanção, ou seja: moralmente devemos nos comportar de certa maneira se não queremos sofrer a sanção que segue o não-cumprimento do dever. 0 dever moral para nós, contudo, é dever, isto é, obriga-nos, porque julgamos o que elemanda como bom. 0 que, portanto, isto significa?

Avaliar al go como bom ou mau significa pressupor um critério ou uma perspectiva, diz Tugendhat, seja ela subjetiva (avaliamos algo como bom subjetivamente, quando o critério da avaliação é 
simplesmente o nosso preferir subjetivo), ou objetiva (neste caso pretendemos que a avaliação seja objetiva, isto é, independente do nosso preferir). N os dois casos, o preferir é presente, só que em um o seu fundamento é subjetivo e, no outro, avaliamos algo como bom, isto é, preferível, porque digno de preferência - e isto significa objetivamente. Avaliações morais pretendem ser avaliações objetivas; devemos porém ainda esclarecer melhor de que perspectiva se trata neste preferir objetivo. D izer que uma ação é boa (por exemplo, dizer: 'cumprimentar-se é bom') parece implicar um emprego não-atributivo da palavra bom, contudo não é assim, segundo Tugendhat. A perspectiva segundo a qual avaliamos as ações ou comportamentos é um conceito de "homem bom"; se dizemos que uma ação é boa significa que ela condiz com o que implicitamente consideramos como ação de um homem bom. 0 conceito de homem bom é, portanto, o critério da avaliação moral. Este é, segundo Tugendhat, o único modo de explicar o uso do termo bom ou mau relacionado à avaliação moral das ações humanas, embora ele não possa ser provado. ${ }^{6}$ O ra, dizer que um homem é bom não significa avaliar nenhuma capacidade específica, técnica ou artística, nas quais os homens podem ser mais ou menos bons, mas "uma capacidade central para a socialização", que é "a capacidade de ser um ente socialmente tratável, cooperador". ${ }^{7} 0$ passo que Tugendhat também não prova, mas pressupõe, é considerar que "0 homem bom" significa um "bom membro da comunidade", "bom parceiro social", "bom cooperador". É típico de uma certa tradição moderna não considerar o homem mais isoladamente, mas como membro da sociedade, que, por sua vez, pode ser considerada como "um sistema de cooperação". 8 Esses pressupostos orientam toda a argumentação de Tugendhat e, finalmente também, sua compreensão da justificação da moral.

Dado o ponto de partida ou o critério para o juízo moral, contudo ainda não é entendida a sua objetividade. 0 conceito do homem bom é, para Tugendhat, apenas um conceito formal, para o qual são possíveis diferentes concepções particulares do que 
significa ser bom membro da sociedade. Podemos perguntar como elas surgem e em que consistea sua objetividade. N uma determinada sociedade, a noção do homem bom é definida pelas normas morais, como diz Tugendhat: "as normas morais de uma sociedade são exatamente aquelas que fixam tais padrões, isto é, que definem 0 que significa ser um bom ente cooperador". ${ }^{9}$ Q uando avaliamos moralmente, isto é, quando aprovamos ou censuramos as ações ou as pessoas, aplicamos, de algum modo, as normas dadas na sociedade, nas quais se expressa o que pela sociedade é considerado ser bom quanto a uma capacidade humana central de cooperar com os outros na sociedade. Isto pelo menos acontece nas situações simples, contempladas pelas normas, nas quais estas podem ser diretamente aplicadas. $\mathrm{N}$ as situações mais complexas, em que acontece um conflito de normas ou interesses, há uma reflexão racional mais complexa. Voltaremos a isto mais adiante.

Essa explicação do conceito do homem bom, contudo, ainda não explica sua objetividade. Ela parece resultar numa circularidade entre as normas e o conceito do bom. Precisamos compreender como surgem as normas e aquilo que elas definem, o conceito do homem bom, e o que as justifica.

Enquanto nos interessa, neste ponto, sobretudo, o papel da razão no juízo moral, podemos perguntar se as normas morais são fruto da razão, ou em que medida a pretensão de objetividade do juízo moral se fundamenta racionalmente. Tugendhat já tinha descartado a noção kantiana da razão como fundamento do dever e também um certo uso instrumental da razão, segundo o qual é racional o que estritamente serve para um determinado fim porque na moral o bom não é entendido simplesmente como bom para. ${ }^{10} 0$ tipo da razão que está em questão na moral talvez se poderia chamar com A. Cortina de "razão intersubjetiva". ${ }^{11}$ As normas morais, segundo Tugendhat, são estabelecidas intersubjetivamente. Como?

U ma vez que não se aceita nenhuma origem transcendente ou metafísica da moralidade, devemos procurá-la na própria 
sociedade, nos membros da sociedade e em seus interesses. 0 conteúdo e a forma da moral coincidem. 0 conteúdo consiste naquilo que por todos é reconhecido como condizente com os seus interesses e assim está a favor dos interesses de todos. 0 princípio racional que poderia explicar este conteúdo Tugendhat reconheceu no conteúdo da moral kantiana, isto é, no imperativo categórico em sua segunda fórmula: "age de tal modo que uses a humanidade, tanto em tua pessoa como na pessoa de qualquer outro, sempre como fim, nunca apenas como meio", 12 o que pelo autor é resumível no imperativo "não instrumentalizes ninguém", ou também é chamado de "moral de respeito universal". Entendido esse imperativo de tal modo que o que ele manda pode ser querido desde a perspectiva de qual quer um (e não apenas desde a perspectiva da pessoa que o pensa), e que as regras que tal princípio estabelece são universais (referem-se a todos e não apenas àqueles com os quais tenho interesse imediato de cooperar) e igualitárias (qualquer pessoa poderia estabelecêlas, portanto as pessoas são consideradas iguais), o imperativo pode ser visto como idêntico ao princípio efundamentação contratual ista da moral. As regras que por ele se estabelecem são simplesmente as regras da cooperação e nada mais. Tugendhat considera, desse modo, que o imperativo categórico éo fundamento natural da moral, daquilo que compreen demos como homem bom, bom parceiro da sociedade. $\mathrm{N}$ ão que $\mathrm{o}$ imperativo categórico resulte analiticamente do conceito do homem bom como bom membro cooperador, mas pelo imperativo kantiano este conceito está explicado de modo natural e plausível. Enquanto Kant e as éticas tradicionalísticas pretendem ulteriormente fundamentar o imperativo nalguma outra instância, Tugendhat pensa que podemos ficar com a plausibilidade da sua origem natural, intersubjetiva. N este momento, não nos interessa a intenção de Tugendhat de fundamentar a sua concepção moral perante as outras concepções como a mais plausível, mas compreender como, na sua concepção, cada indivíduo pode compreender e justificar para si as regras morais, como elas se explicam em termos da racionalidade. 
Poderíamos reformular as idéias assim: cada indivíduo pode racionalmente (o princípio, o imperativo categórico, é racional) compreender 0 que deve fazer para atender os seus interesses e os interesses dos outros, visto que todos aspiram a que os seus interesses sejam atendidos; o bom membro cooperador da sociedade é aquele que atende esta aspiração dos outros e, portanto, considera os próprios interesses na medida em que considera os interesses dos outros, porque essa perspectiva é a única que pode ser universalmente aceita. Isto seria expresso nas regras da cooperação, aquelas que são estabelecidas a partir da perspectiva de cada um. Bom membro cooperador da comunidade seria, portanto, quem cumpre as regras de cooperação e só estas. Isto parece ao nosso autor "demasiado provável", evidente. ${ }^{13}$ Tugendhat, mais adiante, chama esta perspectiva "a partir de qualquer um", com A. Smith, a perspectiva do "observador imparcial". Considera adequadamente os interesses de todos a quem considera imparcialmente, ou seja, somente a perspectiva em que os interesses de todos são considerados imparcialmente é a que pode ser aceita por qual quer um, universalmente. Esta e somente esta é a perspectiva que todos esperam e exigem (ou podem esperar e exigir) de todos. As regras assim estabelecidas passam a ser exigidas mutuamente. N este exigir mútuo Tugendhat situa o fundamento último da obrigação moral, aquele fundamento objetivo que estávamos procurando. Agora compreendemos que ele é intersubjetivo. Cito 0 autor:

Podemos dividir todas as concepções de ser-bom em previamente dadas de modo transcendente (a comunidade moral recebe da autoridade aquilo a que se referem as exigências recíprocas), e aquelas que resultam da própria comunidade - portanto quase imanente, de outro lado. Será que neste último caso não é evidente que o querer ou, como também se diz, os interesses de todos os membros da comunidade fornecem a medida para o bem e isto numa consideração imparcial? É exatamente isto o que é formulado na concepção do imperativo categórico. 
Podemos também expressar isto de seguinte maneira: se 0 bem não é mais dado previamente de modo transcendente, parece então que é apenas a consideração dos membros da comunidade, que por sua vez não pode mais ser limitada, portanto, a consideração a todos os outros (e isto quer dizer ao seu querer e seus interesses), que deve fornecer 0 princípio do ser bom. Formulado de maneira taxativa a intersubjetividade assim compreendida passa a ocupar 0 lugar do previamente dado de maneira transcendente e parece assim construir o único sentido que ainda resta de preferência objetiva. ${ }^{14}$

0 processo da formulação do princípio e da compreensão e aplicação das regras, a meu ver, é um processo racional; quando fala das situações complexas, em que as normas morais ou os interesses de várias pessoas estão em conflito, Tugendhat afirma explicitamente que se trata de uma reflexão moral, que é um procedimento racional; o conceito moral que a pessoa tem - 0 conceito do ser bom ou o imperativo categórico - fornece um critério racional a partir do qual se julga, se reflete, em cada situação concreta. ${ }^{15}$ A ntes, porém, de poder aprofundar as dimensões deste procedimento racional, devemos esclarecer o que a noção de intersubjetividade, em que se fundamenta a objetividade do juízo moral, implica para além da razão. 0 exigir mútuo, o fundamento da obrigação moral, nos conduz à explicitação do papel dos sentimentos na moral, do caráter da sanção que a obrigação moral contém, e, em ultima instância, também das razões que a pessoa tem para decidir comportar-se moralmente.

II -C ompreender a componente racional da moral ainda não significa compreender o fenômeno moral segundo Tugendhat, nem estritamente aquilo a que nos propusemos esclarecer no início, os juízos morais.

O s juízos morais se distinguem do tipo de juízos empíricos, por não serem uma mera constatação racional dos fatos, mas nos 
comprometem afetivamente. Sem esse comprometimento afetivo também sua objetividade, ou obrigatoriedade que eles comportam para o nosso modo de agir, não seria compreensível. ${ }^{16}$ As avaliações morais, de fato, segundo Tugendhat, são sempre acompanhadas pelos sentimentos morais, e estes, por sua vez, são definidos como reações afetivas que se constroem sobre os juízos de valor; o autor fala explicitamente de "sentimentos de desprazer construídos sobre o juízo acerca do desvalor moral" ${ }^{17} 0$ sentimento de indignação acompanha o nosso avaliar uma ação de outra pessoa como má; 0 de raiva, quando esta ação nosprejudica; o sentimento de vergonha ou culpa acompanha a consciência de que a nossa própria ação é má. O ra, a relação entre os juízos e os afetos morais é tal que eles só existem uns em relação aos outros. Os sentimentos morais deixariam de existir se não jul gássemos moral mente, dizTugendhat, porque então não haveria o fundamento para eles. Somente quando compreendemos uma ação como má podemos nos indignar com ela; sem esta avaliação, a indignação perde o sentido. Por outro lado, o juízo moral, a aprovação e a censura só se distinguem de uma mera crítica ou aplauso, que seriam avaliações não-morais das pessoas, por conterem implicitamente o sentimento moral.

Precisamos compreender o porquê desta relação tão estreita entre emotivo e racional na moral, segundo a concepção de Tugendhat. Antes, porém, gostaria de frisar que, com esta complementação dos juízos morais pelos sentimentos, compreendemos também que tipo de sanção está relacionada com as regras morais. A sanção social que todas as regras sociais implicam, no caso das regras morais, consiste no sentimento de indignação e no de vergonha. Essa é a sanção tipicamente moral, isto é, interna, que segue o não-cumprimento do dever moral, e, nesse sentido, relativiza o seu sentido absoluto. 0 sentido preciso da obrigação moral é compreendido por meio dela.

$\mathrm{N}$ a parte dedicada ao papel da racionalidade na moral, compreendemos como se pode racionalmente compreender as normas morais a partir de um princípio racional. 0 ra, efetivamente 
nós "adquirimos" as normas morais no processo da educação moral, que é um processo de formação da consciência moral, juntamente com a formação da própria identidade que, normalmente, faz parte da socialização de uma criança. N esse processo, interiorizam-se as normas presentes na sociedade, juntamente com as reações emotivas (ou precisamente por causa delas, segundo Tugendhat) que acompanham a avaliação dos comportamentos concretos. Com isso, a criança (ou eventualmente um adulto) assume para si "a base normativa comum" da sociedade, aquelas exigências recíprocas que formam as relações interpessoais na sociedade através de uma imagem normativa do homem bom. Esse conceito do homem bom a pessoa deve assumir na sua própria identidade, para poder ser pleno membro da comunidade e poder avaliar moralmente. No fundamento da assunção de uma moral, portanto, está a pergunta: como quero me compreender?, ecom ela a possibilidade, pelo menos teórica, de se decidir a favor ou contra esse conceito ou essa comunidade, a favor ou contra o universo moral com as suas obrigações. Diz Tugendhat:

A formação da consciência moral, segundo vejo a conexão, consiste em que 0 indivíduo, de sua parte, se queira entender como membro da comunidade. Este "eu quero" é naturalmente diferente daquele de que se falava no caso das capacidades especiais. N ele está implicado, em primeiro lugar, que o indivíduo assume em sua identidade (isto é, naquilo com o qual ele se quer entender) este ser-assim, como membro da sociedade ou parceiro cooperador, a que pertence a escala do "bom" e "mau" entendidos de modo gramaticalmente absoluto; e, em segundo lugar, isto significa então que ele se entende como pertencente a uma totalidade de pessoas que, mediante a sanção interna da indignação e da vergonha, exigem reciprocamente umas das outras que estas normas constitutivas da identidade não sejam feridas. ${ }^{18}$ 
$\mathrm{N}$ a base da obrigação moral e antes dela, está portanto um "ato de vontade", uma decisão sobre quem queremos ser, ou se queremos ou não nos compreender moralmente. Este ato de vontade, este querer, relativiza, pela segunda vez, a aparência absoluta do dever moral, segundo o autor, e mostra que somos, em princípio, seres autônomos quanto à moral. Por causa desse querer, também, o fundamento da moral não é de todo racional, porque quando se trata de querer, o que é determinante não são razões, mas motivos. Tugendhat, contudo, sublinha que esse querer não é um "querer decisionista", quer dizer, embora não seja racional, (o autor diz que "certamente nunca [é] explícito e consciente"!19) ele não se dá sem motivos. Voltaremos a isto. U ma vez aceita ou querida a pertença à comunidade, aceita-se o seu ideal do homem bom como a norma própria, à qual está relacionado a partir de então o sentimento de auto estima, e sente-se indignação, quan do suas regras forem feridas pelos outros, e vergonha, quando o agente em questão somos nós próprios. A vergonha e a indignação mostram o "eu quero" implícito. Q ue contudo haja possibilidade de um "não quero", Tugendhat o sustenta com o exemplo do fenômeno do lack of moral sense, que também mostra que a conseqüência de não-assunção do universo moral implica uma mudança radical nas relações interpessoais, que a partir de então podem ser apenas instrumentais, por não haver consciência moral, nem juízos e sentimentos morais, e com isso também não há mais respeito pelos outros. Essa mudança das relações interpessoais é um forte fator motivacional para o "eu quero".

Gostaria de retornar à explicação de Tugendhat sobre como efetivamente "acontece" a assunção da moral e a vinculação da razão com os afetos morais. Segundo a explicação do autor, tudo parece acontecer como num processo de ação-reação: quando al guém com o seu comportamento viola a base normativa comum, os outros reagem com a indignação, pois "no convívio como tal, participam igualmente 0 agente e aquele que está diante dele. A quele que se choca contra esta base comum, de certo modo puxa o tapete de sob 
os pés do outro [...]". ${ }^{20}$ Indignação seria a reação a esse sentir ou reconhecer que "está sendo puxado o tapete de sob os pés", está sendo violado al go que é meu na mesma medida que é dos outros, ou seja, está sendo posta em questão a relação intersubjetiva. Por outro lado, 0 agente percebe que agiu contra a base comum por sentir a indignação dos outros e que esta, por sua vez, significa um pôr em questão também a relação intersubjetiva, e interioriza a norma que delimita as relações e a indignação dos outros, na vergonha perante os outros e perante si próprio (por ter sido rebaixado no sentimento de auto-estima) e no sentimento de culpa (por ter transgredido um ter de exigido). Desse modo, pode ser explicada quase empiricamente a formação da consciência moral de uma criança. N esse ponto, o processo parece estar longe de um procedimento racional. 0 que está pressuposto na consciência moral é que as relações intersubjetivas sejam importantes para nós, para que a reação da indignação dos outros possa ter o significado negativo de sanção. Isto Tugendhat exprime com o conceito do "eu quero" (...fazer parte da comunidade, compreender-me assim), implícito na moral, que acontece normalmente ${ }^{21}$ e, uma vez que 0 querer não se fundamenta em razões, segundo 0 autor, ele aponta para a questão dos motivos para querermos fazer parte do mundo moral.

De fato, este querer não é imotivado, diz o autor; os seus motivos são de tipo afetivo. Isto explica o autor na discussão com Fromm, na qual se mostra que a pergunta que está no fundo da moral, como já viu A ristóteles, é a pergunta antropológica sobre a felicidade. Fromm atribui a isso a necessidade de cada indivíduo de estar relacionado com os outros, de no seu conflito com a falta de autonomia se resolver positivamente, isto é, no sentido de se promover a felicidade apenas numa relação amorosa equilibrada, madura. A procura da felicidade é um fato antropológico e ela se realiza apenas numa relação amorosa autêntica. Toda criança e toda pessoa humana, portanto, procuram esse tipo de relação que, normalmente, é encontrada nas relações íntimas, na família. 0 
que Tugendhat mostra, a seguir, é que a relação de amor autêntico implica já uma atitude de respeito mútuo, que é a atitude moral. 0 respeito e o amor são doistipos diferentes de relações intersubjetivas, que incluem afetos e, num certo ponto, se sobrepõem. Com a motivação antropológica, por assim dizer natural, para desenvolver uma relação amorosa pelo menos com uma pessoa, somos introduzidos afetivamente no universo moral do respeito que porém, necessariamente, estende-se para com todos- necessariamente no sentido do ter de que está no princípio racional, no imperativo categórico. Cito o autor:

$\mathrm{N}$ ão existe amor sem respeito, e uma vez assumida a atitude moral, o "ter de" obrigatoriamente estende-se para além das relações afetivas. [...] Se nós só podemos estar bem numa relação equilibrada de amor e se a relação equilibrada de amor não é possível sem a atitude moral, então temos uma boa razão para nos entendermos moralmente. [...22] Poderíamos encerrar esta articulação de idéias de tal modo, que o motivo para o querer-sermoral seja 0 não-querer-ser-só. ${ }^{23}$

A motivação para entrar no universo das exigências mútuas consiste, portanto, neste "não-querer-ser-só", que leva ao "eu quero" (...estar com os outros e, por isso, entrar no sistema de exigências mútuas) necessário para a moral. Essa motivação afetiva para Tugendhat, contudo, não énada compul sória. A pessoa pode manter sua autonomia mesmo diante de uma "necessidade biológica":

D everíamos manter-nos isentos de uma tendência dogmática de Fromm. Fromm tende a dizer: porque o homem é desta maneira (por exemplo, não quer ser só), ele tem de... $\mathrm{N}$ ão necessitamos de uma tese antropológica tão forte, e podemos simplesmente dizer: se tu não queres ser solitário, tens de..., mas está na tua liberdade preferir uma vida solitária (ou não). A penas podemos mostrar que tudo está 
relacionado com o lack of moral sense. $N$ ão existe um "tem de" absoluto, nem moral e nem motivacional. ${ }^{24}$

Com essa compreensão dos sentimentos, temos agora mais elementos para compreender como, em cada pessoa, se dá a interação entre racional e emotivo na vida moral; a razão e os sentimentos são, pois, imbricados ${ }^{25}$ na nossa consciência moral, que se sustenta "sobre um tecido complexo de fundamentos e motivos", ${ }^{26}$ segundo a expressão do autor. Na próxima seção tentaremos aprofundar a compreensão dessa interação.

III -A té este ponto, compreen demos como Tugendhat explica o próprio conceito moral baseado em Kant, interpretando-o e corrigindo-0. ${ }^{27} \mathrm{~A}$ ética de Kant éuma ética de regras, ${ }^{28}$ que estabelece um mínimo de conteúdos e exigências obrigatórios, sobre os quais, de fato, podemos e devemos concordar para uma convivência ou cooperação pacífica na sociedade. Estenúcleo mínimo de conteúdos é dado pelo contratualismo, e corresponde também ao que Tugendhat chamou de "consciência moral existente". Seu princípio explicativo é princípio de imperativo categórico, que éum princípio racional. Os juízos morais, baseados nas regras e, assim, neste princípio, são, portanto, um julgar racional que pretendemos seja objetivo e universalmente válido. Essa objetividade, por sua vez, se fundamenta, ultimamente, no nosso aceitar as normas e o critério de julgamento, presente nelas - que é um conceito de homem bom - como fazendo parte de nossa identidade, da nossa vida; nisso consiste o elemento voluntarista da ética de Tugendhat.

Poderíamos agora esclarecer melhor a questão da imbricação entre fundamentos e motivos. Tugendhat sustenta que um fundamento é o fundamento para a verdade de enunciados, de juízos. Enquanto a moral implica juízos morais, estes somente podem e devem ser feitos e sustentados racionalmente, a partir de um princípio racional. 0 princípio nos proporciona uma imagem do homem bom, que serve como critério daquilo que julgamos como 
bom ou mau, e este julgar deve ser coerente com a própria imagem. $\mathrm{N}$ isso consiste a racionalidade da moral. U ma vez assumido este critério, nós podemos discutir com os outros a respeito da sua plausibilidade, da sua validade, à base de razões. Tugen dhat se propôs argumentar a favor da maior plausibilidade do seu conceito moral (a sustentação de um conceito qualquer não pode hoje pretender mais do que a plausibilidade, isto é, ele não está sustentado absolutamente). 0 ra, essa racionalidade não fundamenta, porém, 0 fato de nós julgarmos e agirmos moralmente. 0 fato de aceitarmos um critério qualquer de julgamento, uma imagem do homem bom e 0 fato de agirmos de acordo com ela, pressupõe o momento decisionista: o querer. A aceitação de um sistema moral é, de fato, já uma ação e uma ação não pode ser fundamentada em razões, mas apenas justificada pelos motivos. Para agirmos, precisamos de motivos, de metas, e as metas nos são pré-dadas pela nossa afetividade, diz Tugendhat. O s sentimentos por si não são morais, não é que eles possam fundamentar a moral, como pensava Schopenhauer; de mesmo modo a razão, por si, não fundamenta a nossa ação, como sustentava Kant. O s sentimentos nos motivam, ou seja, o princípio ou norma moral nos motivam emotivamente, por meio da sanção interna, por meio da nossa consciência dos vínculos intersubjetivos. Q uando não têm esse elemento emotivo, eles, de fato, não valem para nós. Esta é a explicação do fenômeno do lack of moral sense, e também a razão por que o contratualismo não explica suficientemente a moral. Q ue nós queiramos ser morais, pertencer a uma comunidade moral através dos seus vínculos morais, diz Tugendhat, é um ato de nossa autonomia, que é um ponto intransponível. N esse sentido, também nenhuma compreensão empírica de quem nós sejamos, de quem é o homem e como ele age - nenhuma compreensão psicológica ou sociológica dos motivos que repousam no fundo das nossas ações pode significar a fundamentação da obrigação moral; esta reside na nossa decisão pessoal, sustenta 0 autor, pois "do ser não segue o dever": 
Quem se coloca a pergunta 'quero eu fazer parte da comunidade moral?', tem de perguntar-se: 'quem afinal eu quero ser, em que reside para mim a vida e o que depende para mim disto, que eu me compreenda como pertencente à comunidade moral?' Por isso, o momento decisionista tem que ser simplesmente destacado, porque tudo que podemos nomear em motivos para nosso interlocutor e para nós mesmos, apenas pode [se] mostrar com base em nosso saber antropológico, somente pode mostrar quanta outra coisa seria jogada fora junto com nossa pertença a uma comunidade moral. D esta maneira a decisão deixa-se apoiar racionalmente, mas não substituir. ${ }^{29}$

IV - G ostaria de complementar esta exposição com a questão que 0 autor se coloca na segunda parte do seu livro, quando se confronta com as diversas éticas que não partem do princípio kantiano da moral. Trata-se da seguinte questão: se não deveríamos alargar a moral para além das regras de cooperação. Tugendhat, como vimos, explica e constrói argumentativamente o seu conceito moral a partir da ética kantiana de regras; o seu núcleo consiste no princípio racional, a partir do qual são construídas regras simples, que são regras negativas, no sentido de proibirem certas ações que claramente são discerníveis como imorais a partir do imperativo categórico. Ora, este conceito moral parece não considerar e esclarecer suficientemente as "obrigações positivas". A pergunta, portanto, se devemos alargar a moral para além dessas regras para as obrigações positivas conduz 0 autor a considerar as chamadas éticas de virtudes ou de atitudes. Penso que com esta reflexão e com o alargamento da sua concepção, o autor esclarece ulteriormente a questão do papel da razão e do sentimento, dos motivos morais, como também o "momento decisionista" na moral.

Com A. Smith o autor reconhece que, no nosso convívio interpessoal, não avaliamos somente as ações das pessoas como boas ou más, mas também as correspondentes reações afetivas, os sentimentos morais - avaliamos a sua adequação ou não. Smith 
sustenta isto dizendo que o que nós desejamos para a nossa vida do convívio com as pessoas não é apenas o cumprimento de regras negativas, mas sobretudo um partilhar os afetos, a harmonia afetiva. Para que os afetos morais possam ser partilhados, eles devem ser adequados a situações, isto é, devem ser tais que uma pessoa qualquer, confrontada com a mesma situação, possa senti-los. Por isso, Smith introduz o conceito do "observador imparcial", aquele que julga imparcialmente as situações e os afetos morais e a sua conveniência ("princípio de conveniência"), e sustenta que a harmonia afetiva se baseia nas virtudes morais de sensibilidade (para com os afetos dos outros) e de autocontrole (dos afetos próprios), que seriam as virtudes que correspondem ao princípio de conveniência e o realizam. 0 juízo moral das situações e dos afetos se daria, pois, a partir da perspectiva de quem quer partilhar os afetos com os outrose, não, a partir da perspectiva de quem julga se pode desejar para si as ações e situações dos outros, que seria a perspectiva do imperativo categórico.

Tugendhat parece concordar com a idéia de que o desejo de partilhar os afetos seja um nosso fator motivacional para a moral vimos que sustenta com Fromm que o nosso motivo básico é a necessidade de ser amado e de amar. O ra, el e simplesmente diz que as atitudes ou as virtudes que esse desejo motiva podem ser explicadas também a partir do princípio kantiano, imperativo categórico, ou melhor, só a partir dele elas se tornam realmente morais, isto é, universalmente exigíveis:

devo comportar-me assim como se deseja na perspectiva de qualquer um; e o que cada um quer dos outros não é apenas que ele não seja lesado, que se cumpra a palavra com ele, e que na necessidade seja ajudado, mas ele quer igualmente que nos relacionemos com ele afetivamente $\mathrm{e}$ que por sua vez se dê tal (se domine), de modo que seja possível encontrar-se com ele afetivamente. É, portanto, 0 próprio princípio kantiano bem entendido que se estende para além das obrigações de cooperação e que inclui a 
abertura afetiva recíproca exigida por Smith. As duas virtudes fundamentais [...] de fato são exigidas pelo princípio da moral universalista, como já o estabelecera Kant; são atitudes exigidas moral e universalmente. ${ }^{30}$

0 princípio kantiano, portanto, não fundamenta só as regras, mas também as atitudes com as quais entramos nas relações interpessoais. Aliás, o próprio respeito, que Tugendhat, como Kant, considera universalmente exigível - e que está na base de todas as ações particulares - é uma atitude: a de reconhecer o outro como sujeito de direitos, como autônomo e livre e também na sua autoestima.

Juntando a perspectiva do observador imparcial (dos afetos morais) àquela de quem julga a partir dos interesses de qualquer um, podemos esclarecer a questão da motivação ulteriormente. 0 que nos motiva moralmente é o desejo de sermos amados e aprovados de forma justificada, ${ }^{31}$ isto é, não nos satisfaz apenas sermos de fato aprovados pelos outros, mas sermos dignos de ser aprovados, de sermos aprovados objetivamente. 0 sentido do aprovar consiste precisamente nisso: que se julgue objetivamente. Por isso, o aprovar efetivo, empírico, dos outros, nunca é a medida do ser digno de aprovação. D evemos, portanto, distinguir entre ser aprovado e ser digno de aprovação, eisso significa também distinguir entre desejar empiricamente algo, os interesses empíricos das pessoas e a consideração objetiva dos interesses, sob a perspectiva do juiz imparcial. O ra, essa perspectiva imparcial não pode ser uma perspectiva fora da comunidade real - não há um ponto transcendente à sociedade real, segundo o autor, mas ela também não resulta empiricamente dos interesses das pessoas reais. A perspectiva do observador imparcial é uma perspectiva dos que de fato julgam, é uma "idéia regulativa da própria aprovação". ${ }^{32}$ Isto, porém, aventa a seguinte questão: como sabemos que a perspectiva real de quem julga é uma perspectiva imparcial? Tugendhat é obrigado a refletir ulteriormente sobre o papel das razões no juízo moral, sobre a 
validade das normas dadas numa determinada sociedade, sobre onde o nosso juízo pode se enganar quanto à perspectiva normativa. 0 primeiro nível, que não diz respeito propriamente ao critério normativo, seria a falta de informações corretas sobre uma dada situação. U m nível mais problemático existe onde há situação complexa de um conflito entre vários interesses, ou várias normas dadas. Tratarei disso mais adiante. 0 terceiro nível citado por Tugendhat se refere à adequação das normas dadas na sociedade ou, como ele diz, à pergunta sobre quem constitui a comunidade moral. Dizo autor:

Somente podem estabelecer o que compreendemos por um ser humano bom aquelas normas que, na passagem dos juízos morais de uma sociedade para os de outra, permanecem invariáveis; nisto naturalmente, bem como na passagem para uma pessoa qualquer, deve-se pressupor que as outras sociedades por sua vez desistam de seus juízos morais auto-sincráticos. Não se trata do denominador comum inferior dos sistemas morais fáticos. ${ }^{33}$

Parece-me que, nesse ponto, 0 autor não é consistente. Se nenhum sistema moral fático em si significa a norma de juízo - isto é, se assim como nenhum dos diferentes interesses empíricos existentes na sociedade significa o critério de jul gamento, mas todos eles devem ser avaliados imparcialmente, assim também nenhum sistema dado da moral, nenhum conceito concreto do homem bom dado pelas normas, representa por si aquele conceito que é normativo, aquele que realiza a perspectiva do juiz imparcial - , mas à luz do princípio do juiz imparcial nós podemos avaliar diferentes sistemas morais (queisto deve ser possível, resulta do próprio sentido da exigência objetiva do aprovar), então não parece claro por que um dado número de normas, aquelas que num dado momento da história coincidem em vários sistemas dados, dão mais certeza de representarem adequadamente a perspectiva imparcial. Isto levaria à conclusão de que o critério de juízo pode ser empírico: o que nos 
vários sistemas aparece invariável, é normativo. 0 autor provavelmente não concordaria. As normas que coincidem em vários sistemas dados são poucas, e Tugendhat comenta que a imagem normativa do homem bom não pode resultar num denominador comum mínimo, inferior aos sistemas dados. Ele, de fato, já tinha alargado a obrigatoriedade moral para além do núcleo mínimo de regras. A questão no presente problema, a meu ver, é como discernir a norma, o que é objetivo, o digno de ser aprovado, entre o que é empiricamente aprovado e intersubjetivamente exigido. 0 nosso referencial das exigências intersubjetivas pode não ser a nossa comunidade real?

U m outro nível de dificuldade seria a validade do próprio critério normativo, isto é, do imperativo categórico. Aqui o autor argumenta novamente a favor da maior plausibilidade desse princípio, sobretudo diante do princípio utilitarista. Não énecessário trazer aqui a sua argumentação.

G ostaria de voltar brevemente à questão de como discernir a perspectiva imparcial, quando estão em questão vários interesses, várias normas, porque nesse ponto 0 autor esclarece de novo 0 elemento decisionista, presente agora também no interior da reflexão moral racional (para o qual parece apontar também a dificuldade acima).

N os casos simples, o elemento normativo do nosso juízo, a perspectiva imparcial, pode ser discernido e "consiste em quetodos exigem moralmente de todos comportarem-se de tal maneira que não lesem os respectivos bens, ou que os protejam". ${ }^{34}$ Desse princípio, resultam, de fato, al gumas normas básicas universais. Mas quando se trata de conflito de interesses de vários, "aquele que julga tem que tentar colocar-se simultaneamente na situação de cada um e comparar em sua importância os diversos interesses, como se admite, que também qualquer outro os ponderaria". ${ }^{35}$ Isto, certamente, não é facilmente discernido e, como diz Tugendhat, não se tem garantia de que o resultado é realmente "idêntico ao que chegaria qualquer outro". N essas situações, decidimos intuiti- 
vamente, interpretamos intuitivamente a aplicação do princípio moral. A conclusão do autor é que a reflexão moral é um procedimento racional que parte de um princípio de juízo, mas que contém também os elementos fortemente intuitivos, por isso, os resultados não podem ser claramente deduzidos.

A solução é freqüentemente uma questão de decisão pessoal. [...] Este procedimento do juízo fornece um núcleo racional para a reflexão concreta; fica contudo aberta nas margens, e em todas as questões morais profundas implica um irredutível fator decisório pessoal. ${ }^{36}$

\section{Conclusão}

$\mathrm{Na}$ realidade, a justiça não me engloba no equilíbrio da sua universalidade - a justiça intima-me a ir além da linha recta da justiça e, a partir daí, nada pode marcar o fim desta marcha, por detrás da linha recta da lei, a terra da bondade estendese infinita e inexplorada, tendo necessidade de todos os recursos de uma presença singular. ${ }^{37}$

Este último elemento e também a dificuldade mencionada anteriormente sobre como discernir o que é digno de ser aprovado, dentre 0 que é empiricamente aprovado e mutuamente exigido numa dada comunidade, apontam, a meu ver, para uma tensão entre a fundamentação da obrigatoriedade moral nas exigências intersubjetivas, que é uma fundamentação (justificação) via sentimentos nas relações intersubjetivas concretas (mesmo que interiorizadas na consciência) e a exigên cia de objetividade do julgar que está no próprio sentido de julgar, de aprovar ou censurar. As regras morais - aquelas que nos podem fazer perceber claramente as exigências mútuas numa comunidade eque nos marcam, segundo 0 autor, com 0 sentimento de obrigatoriedade, que imprimem em nós os contornos da consciência pela indignação dos outros e pela 
vergonha diante deles - só podem se referir ao que é exigido minimamente entrenós. N as questões morais mais profundas, quer dizer, naquilo que vai para além do mínimo e universalmente exigido, não existem regras. Existe a obrigatoriedade de seguir um princípio moral, eventualmente de desenvolver certas atitudes, mas o fato de saber o que isto significa na prática, de como aplicar 0 princípio, não é univocamente percebido e, portanto, nem exigido. O s problemas são discernidos e resolvidos pessoal mente, e o sentido de obrigatoriedade também pode provir somente da consciência pessoal. Q ue de fato assim aconteça não se pode negar. Isto também explica a diferença na acuidade de consciência moral entre as pessoas, a diferença na percepção das nossas obrigações, nossas responsabilidades. A pergunta que se pode aventar, a partir daqui, é como justificar, nesse tipo de questões, o sentimento da obrigatoriedade na consciência das pessoas, uma vezque atéaqui se sustentou que 0 sentido da obrigatoriedade moral provém das exigências mútuas. Q uando não podemos de forma clara, mútua, estabelecer o que é moralmente bom, não podemos igualmente exigi-lo um do outro. Mas não podemos ficar só com o que é clara e intersubjetivamente percebido, com este núcleo mínimo, no nosso convívio. 0 autor reconheceu isto e alargou o sentido da moral para além desse mínimo, para a terra das virtudes. N este âmbito, porém, a obrigatoriedade moral de optar pelo que é digno de preferência parece não se fundamentar mais no exigir mútuo, no querer evitar a indignação dos outros, porque pode não haver um exigir comum. $N$ ão obstante isso, na consciência se apresenta a exigência moral de optar pelo que é digno de preferência.

Sustento, com A. C ortina, que a moral não é apenas questão dos mínimos, do que minimamente devemos exigir um do outro, mas é uma questão "do máximo", da perfeição do homem, da sua realização e da sua felicidade, ${ }^{38}$ da sua identidade, o que, no fim das contas, não consiste no cumprimento das regras mínimas. Como nessa questão é difícil orientar-se pelas exigências mútuas, em que nos orientamos? N uma imagem de homem bom, que porém não é 
deduzida das exigências dos outros, mas pode ser eminentemente pessoal, permanecendo, contudo, normativa.

Parece, portanto, que a justificação da moral pelas exigências mútuas explica a obrigatoriedade das normas morais mínimas, mas não é suficientemente clara se procuramos uma ética "do máximo" para o homem. ${ }^{39}$ Se nos interessam, contudo, "os máximos", talvez seja necessário repensar a proposta de Tugendhat.

ABSTRACT: The paper pretends to explain a Tugendhat's explication of the justification of the moral obligation, implicit in the moral judgement, in which rational and emotional elements are present. The moral judgements, whereas racional proceeding, envolve a pretension to objectivity, that can be explicated by the kantian categorical imperative, interpreted as mutual demanding for the universal and imparcial respect of the interests of everyone. The moral obligation, however, implies also a will to take part of a moral community and of the intersubjective exigences which are assumed through an interiorization of sentiments that go along with moral approvals or disapprovals. This explication of the moral exigences seems satisfactory for justificate a minimal nucleus of moral norms shared by the community; the paper points to a difficulty of this justification of the moral obligation in the case of the lack of shared moral norms and in the case of a discrepancy between moral exigences and what is empirically approved in the society.

Key words: moral judgements, reason, sentiment, justification, intersubjectivity.

\section{Notas}

1 Tugendhat, E. I gualdade e universalidade na moral. In: Brito, A. N e Heck, J. N. (O rgs.). Ética e política. Goiânia: Editora da UFG, 1997. p. 46.

2 Tugendhat, E. Lições sobre ética. Petrópolis: Vozes, 1997. p. 34.

3 Sobre o tipo da sanção implicada nas normas morais falaremos mais adiante, na parte do trabalho dedicada ao papel dos sentimentos, visto queesta sanção é principalmente emotiva, segundo Tugendhat.

4 Aqui já se torna compreensível a crítica que Tugendhat faz à fundamentação kantiana da moral: para Kant normas morais são normas derazão, sem contudo incluírem nenhum fim prático 
- são racionais em si e não em função de um fim. Kant tinha introduzido um sentido novo, metafísico, da razão, diferente do "sentido comum", para diferenciar imperativos hipotéticos do categórico; esse sentido metafísico da razão para Tugendhat é uma construção filosófica que não fundamenta nada.

5 Tugendhat, 1997, p. 50.0 grifo é meu.

6 Ibidem, p. 59.

7 Ibidem, p. 61.

8 Ibidem, p. 122. Esta definição da sociedade encontramos por exemplo em Rawls, que porém, na sua compreensão da sociedade e dos problemas políticose morais, se insere na tradição contratualista. Para a explicitação de al guns dos seus pressupostos, cf. A. Cortina, Etica minima. Introduccion a la filosofia practica. 4.ed. M adrid: Editorial Tecnos, 1994, p. 198-198. Também F. Rodrigues, no seu artigo "A moral do respeito universal e igualitário de E. Tugendhat" (em A. N. Brito e). N. H eck (O rg.). Ética e política, Goiânia: Editora U FG, 1997, p. 115-131) nota esta passagem, não explicitamente esclarecida, na obra de Tugendhat, de uma abordagem formal da moral (que pode conter o conceito do homem bom) para uma “idéia conteudística de bem" (que está presente na idéia do homem como ente cooperador numa sociedade).

9 Lições sobre ética, p. 61.

10 Isto talvez se poderia também questionar, considerando o que o autor diz sobre a relativização da obrigação moral pela sanção. Se tomamos isto seriamente, se assumimos que a pressuposição da sanção está essencialmente presente na nossa compreensão da moral, poderíamos reconstruir os juízos morais da seguinte maneira: fazer isto ou aquilo (respeitar os outros, por exemplo) é bom para ser considerado bom membro da comunidade e não ser reprovado e rejeitado.

11 A. Cortina, na obra citada, apresenta a distinção rawl siana entre racionalidade e razoabilidade (esp. razonabiblidad): enquanto a 
racionalidade seria marcada por uma razão individual, monológica, como um cál culo de meios adequados para al cançar determinadosfins, a razoabilidade tem o caráter social, porque se entende apenas pela relação com os outros indivíduos com os quais se pretende cooperar. "A razão moral é a que visa estabelecer e fomentar a intersubjetividade, não a que discorre monologicamente sobre os meios mais adequados para alcançar o próprio bem. N este sentido, também Rawls aposta nesta acreditada tradição ético-política, de raiz tanto liberal como socialista, que vêna realização da intersubjetividade o momento da moralidade. A razão prático-moral é, desde Kant, intersubjetiva, não monológica [...]". (Co ortinA, op. cit., p. 198-199).

12 Lições sobre ética, p. 87.

13 Se consideramosquea identificação da noção do "bom homem" com o "bom parceiro cooperador da sociedade" éum pressuposto anteriormente escolhido, este raciocínio aparece circular na sua evidência.

14 Lições sobre ética, p. 94-95. A este modo de fundamentar intersubjetivamente as exigências morais, num texto posterior a Lições, intitulado "O contratualismo na moral", Tugendhat não hesita em chamar de "acordo "ou "contrato moral", e assim explicitamente aproxima a sua concepção da moral à de contratualismo, que ele, na presente obra, aceita quanto ao conteúdo moral, mas critica como uma "quase-moral", por ser insuficiente para explicar todas as dimensões da moral (nomeadamente, a consciência, os sentimentos morais e a universalidade do juízo moral). Vimos, porém, que o contratualismo está implicitamente presente também na sua idéia de homem como ente cooperador.

15 L ições sobre ética, p. 357.

16 N um outro texto posterior às Lições sobre ética, intitulado "Reflexões sobre o que é que significa justificar juízos morais", Tugendhat esclarece explicitamente que o que carece ser justifi- 
cado nos juízos morais é precisamente a "irritação emocional" que os acompanha.

17 Lições sobre ética, p. 21.

18 Ibidem, p. 63-64.

19 Ibidem, p. 65.

20 Ibidem, p. 62.

21 Ibidem, p. 65. 0 fenômeno do lack of moral sense é reconhecido pelo autor como um fenômeno patológico raro, segundo a psicopatologia; não obstante, ele serve para mostrar que, nas circunstâncias normais, um "eu quero" está presente na base da moral.

22 Ibidem, p. 301. "Estas considerações são apoiadas pelo dado empírico que aquelas crianças que não podem construir relações de intimidade obviamente padecem sob um lack of moral sense."

23 Idem, ibidem.

24 Ibidem, p. 302.

25 A expressão é de Delamar J. V. Dutra, em "A análise do que é uma moral e a questão da sua fundamentação: um estudo das Lições sobre ética de Tugendhat", Veritas, n. 1, p. 221-229, mar. 1999.

26 Lições sobre ética, p. 30.

27 A novidade de Tugendhat, em relação a Kant, é principalmente a introdução dos afetos no fenômeno moral, e a explicação empírica deles, que resulta numa tradução empírica da noção do respeito (relacionado em Tugendhat com o reconhecimento empírico da autoestima), é, portanto, um elemento empírico na fundamentação da moral. Cf. A. Cortina, Ética sin moral. 3.ed. M adrid: Tecnos, p. 231.

28 Ibidem, p. 246.

29 Ibidem, p. 104. Estas afirmações parecem contradizer uma afirmação anterior de Tugendhat de que este querer básico 
"certamente nunca é explícito e consciente" (p. 65); se se pode apoiar em razões e motivos, então ele é consciente; se não é consciente, não éuma decisão pessoal, mas algo que apenas tem causas (biológicas, psicológicas, sociais...?), e se é algo causado, de modo algum representa a nossa autonomia moral. Isso evidentemente poria em questão toda a teoria de Tugendhat. As razões e motivos, pois, influenciam a nossa vontade, mesmo que não a determinem.

30 Ibidem, p. 319.

310 desejo de ser amado nos motiva a uma atitude moral em relação aos que nos são próximos, cujo amor nos interessa assim Tugendhat explicou a motivação moral a partir de Fromm. $M$ as esse desejo não nos pode motivar a sermos morais para com todos, porque não esperamos uma relação amorosa de todos. A motivação à atitude moral universal pode ser explicada pelo desejo de sermos aprovados moralmente por todos - esta é a contribuição da ética de Smith.

32 Ibidem, p. 338.

33 Ibidem, p. 339.

34 Ibidem, p. 355.

35 Idem, ibidem.

36 Ibidem, p. 357. U m exemplo desse procedimento racionalintuitivo que traz a marca da interpretação pessoal éa proposta de solução para a questão da nossa obrigação moral diante das crianças não nascidas, na nona lição.

37 Levinas, E. Totalidade einfinito. Lisboa: Ed. 70, 1988. p. 223.

38 "(H á) o perigo de identificar a dimensão moral do homem com as normas legitimadas por consenso, equiparando o moral com a moral cívica e esta com o mundo das normas. 0 moral [...] transcende em muito o âmbito do 'deôntico', o âmbito do dever e das normas. [...] 0 moral abarca, certamente, 0 terreno das normas e da moral civil, porém estas - não o esqueçamos - 
tendem a ser positivadas e a converter-se em direito. Assim se constitui, pouco a pouco, esse mínimo de leis consensuais, plasmadas em normas positivas, que constituem as regras de jogo da vida cidadã. Porém os projetos morais, as concepções do homem de que falamos [...], são propostas de máximos: buscam ideais de homem e de felicidade a partir da arte, da ciência e da religião; a partir daquela trama, enfim, de tradições que configuram a vida cotidiana. [...] À moral preocupam também os máximos, não somente os mínimos normativos; preocupamna também os valores em que vale a pena empenhar a vida" (CORTINA, 1994, p. 158-159).

39 Kohlberg éum autor contemporâneo que aponta para os estádios de desenvolvimento moral, que são os estádios do máximo desenvolvimento pessoal de um indivíduo, em que, segundo ele, o indivíduo se orienta pelos princípios morais enão pelas normas dadas. Privilegiar o elemento racional é o fundamento da tese deste autor.

\section{Referências}

Cortina, Adela. Etica minima. Introduccion a la filosofia practica. 4.ed. Madrid: Editorial Tecnos, 1994.

. Ética sin moral. 3.ed. Madrid: Tecnos, 1995.

Dutra, D elamar J. V. A análise do que é uma moral e a questão da sua fundamentação: um estudo das lições sobre ética de Tugen dhat, Veritas, n. 1, p. 221-229, mar. 1999.

RodRIGUES, Fernando. A moral do respeito universal e igualitário deE. Tugendhat. In: Brito, A . N.; H ECK, J. N . (O rgs.). Ética epolítica. Goiânia: Editora da U FG, 1997. p. 115-131.

TugendHAT, Ernst. Igual dade e universalidade na moral. In: BRITO, A. N .; HECK, J. N . (O rgs.). Ética e política. G oiânia: Editora da U FG, 1997. p. 45-60.

. Lições sobre ética. 2.ed. Petrópolis: Vozes, 1997. 
. 0 contratualismo na moral. In: Brito, A. N. (O rg.). Ética: questõ̃es de fundamentação. G oiânia: U FG / U nB, 2002.

. R eflexões sobre o queéque significa justificar juízos morais. In: BRITo , A . N . (O rg.). Ética: questões de fundamentação. G oiânia: UFG/UnB, 2002. 